\title{
It takes a global village
}

$\mathrm{F}$

rom here in Nigeria, it seems the whole world is losing its fight against HIV/AIDS. The rapid spread of HIV/AIDS infection is decimating this country's adult population: 3.8 million of our population are infected with HIV/AIDS. ${ }^{1}$

Tragically, whenever we care for young adults who are dying, we find children swept up in the process. In Nigeria alone, there are over one million orphans whose parents have died of HIV/AIDS and over 50 ooo children ${ }^{1}$ whose parents are dying of HIV/AIDS.

What are we going to do?

In many rural villages, a whole generation of parents has been wiped out. Only the grandparents and children are left, and the village cannot survive. In traditional village life, orphaned children were relocated within the extended family/friends network. The present reality is that orphans whose parents died of HIV/AIDS are often being rejected by the extended family and friends because of fear of contracting HIV/AIDS from the orphans. These children may already have assumed adult responsibilities prior to their parent's death, as family resources are shifted to the care of the infected person. In many villages, 9-year-old children are acting as "Mum and Dad" to younger brothers and sisters. The children have to walk miles to collect firewood and water, grow their own food and cook it, as well as supervise young ones and maintain their houses. They have no resources and no adults to help them.

Following the death of a man, the tradition of patrilinearity may deny the wife and the children their right to stay where they have been living.

One answer may be to build residential institutions to provide education and care for these orphans, but this may not be the best answer. Orphaned children need to be integrated into family and community life as much as possible. Housing and educating these children separately reinforces the separation and stigma. Isolation from village community life may make integration more dif-

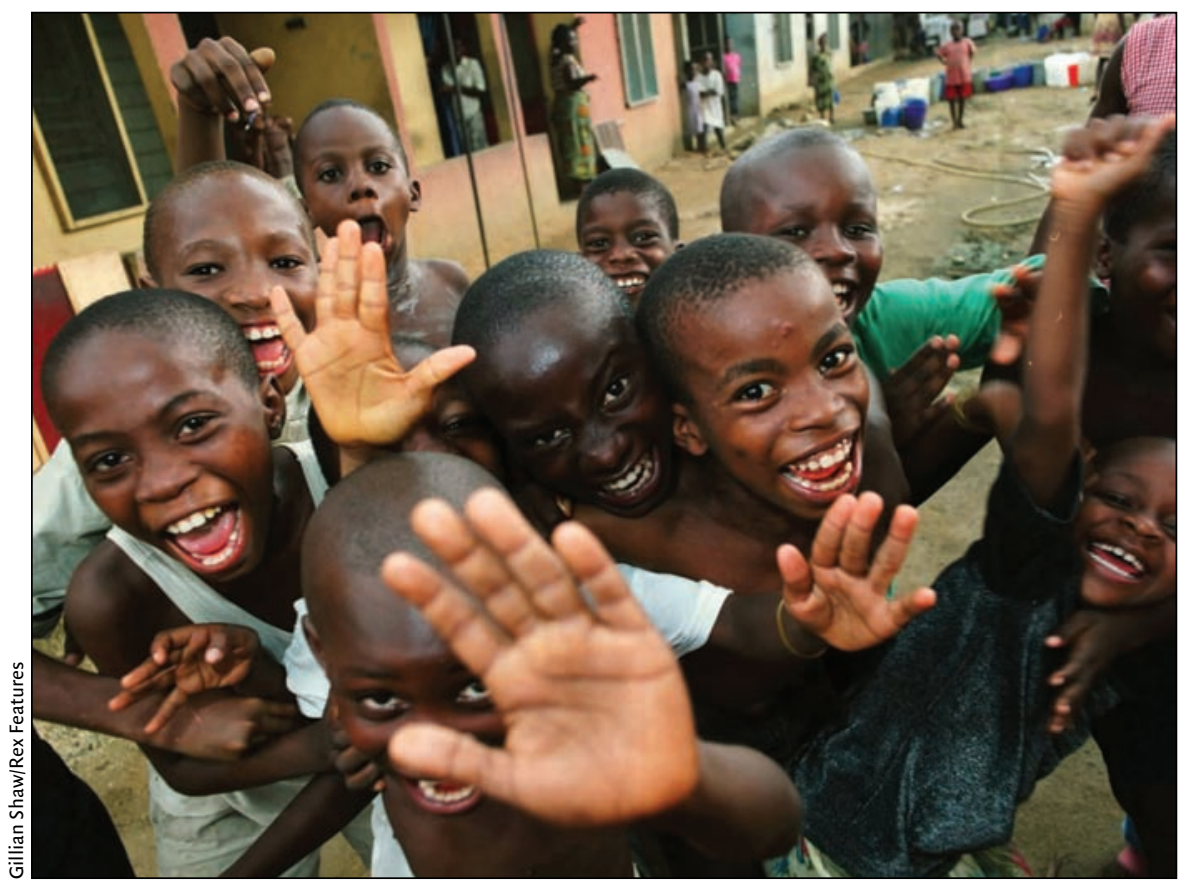

Children of a global village - What future can we give to them?

ficult later as they become adults. They may have difficulty finding husbands and wives as they do not belong and most of them will become a "high-risk" group: they are more likely to become sexually active early and risk infection with HIV. Lacking social and family support, they are more vulnerable to criminality and prostitution, and a great number of them might join the ranks of street children.

At present in Nigeria, one household out of every ten is already caring for an orphan. Without support for extended families, they will become reluctant to take in additional children.

One effective way to help these families in a country such as Nigeria is to provide school fees. Often this is all that is needed. The children are then back to school with their friends. They are supervised and may even be fed in the middle of the day. Right now, local schools are half empty, because HIV/AIDS orphans can no longer afford to attend.

As in every area of this terrible epidemic, it is easy to feel totally overwhelmed. Where do we start? How do we begin to tackle such a vast, global, growing problem? The answer is we have to start somewhere. As has often been said, we cannot change the whole world, but we can change someone's world somewhere. Whenever we begin caring for those with AIDS, we are faced with the terrible thought that even as a growing number of people are dying of this disease, many more are becoming infected. If we cannot cure it and the virus is spreading so fast, then we must urgently do all we can to prevent further tragedy through the fate of orphaned children.

As scarce resources have to be shared, strategies need to be costeffective and sustainable, utilizing local resources to assist and relieve the burden placed upon the families by the huge number of orphans.

\section{Ogboi Sonny Johnbull}

Department of Community Medicine Ahmadu Bello University, Nigeria

\section{REFERENCE}

I. Federal Ministry of Health. Department of Public Health. National AIDS/STD Control Programme Technical Report. April 2003. 